\title{
A study to assess the effectiveness of structural teaching programme on knowledge regarding the oral rehydration therapy in management of diarrhea among mothers of under five children in selected community.
}

\author{
Pushpendra Kumar ${ }^{1,}$ Vikas Choudhary ${ }^{2}$, Titi Xavier Mangalathil ${ }^{3}$ \\ ${ }^{1}$ Assistant Professor, Arawali college of Nursing, Sikar \\ ${ }^{2}$ Lecturer, M.M College of Nursing, Mullana \\ ${ }^{3}$ Associate Professor, Rajasthan College of Nursing, Sikar
}

\begin{abstract}
Diarrhea is one of the top five causes of death among infants and under-five children in India ${ }^{[1]}$, despite the availability of easily implementable interventions and existence of National Guidelines for management at the community level. Oral rehydration therapy (ORT) with oral rehydration salt (ORS) solution remains the cornerstone of appropriate case management of diarrheal dehydration and is considered the single most effective strategy toprevent diarrheal deaths in children. Diarrheal illnesses are the leading causes of childhood deaths beyond infancy; it is responsible for 24\% of the deaths in children aged 1-4 years, and 17\% of all deaths in children 5-14 years. ${ }^{[1]}$.Diarrhea is a common disease and is one of the major determinants of death in pediatric population of the developing Countries.Diarrhea is mainly develop by the lack of healthy practices such as improper breast feeding, unhygienic weaning practices unsafe drinking water, poor practice of hand washing and malnutrition. The mother of rural community areas are unaware about causes sign and symptoms of diarrhea and use of oral rehydration therapy for management of diarrhea ${ }^{[2]}$ In this context, it was attempted to assess the effectiveness of a structured teaching programme on knowledge regarding the oral rehydration therapy in management of diarrhea among mothers of under five children. A quasi experimental approach with purposive sampling technique was used in the study. The findings of the study shows that the difference between pre-testmean knowledge score of control and experimental group was statistically non-significant at $p<0.05$ level whereas the difference between post-test mean knowledge score of both groups was statistically highly significant at $p<0.001$ level. It was thus concluded that the structured teaching programme was effective in raising the knowledge level of mothers of under five children regarding the oral rehydration therapy in management of diarrheaand there was statistically significant effect of age, educational status and occupation on knowledge level of mothers of under five children regarding the oral rehydration therapy in management of diarrhea.
\end{abstract}

Keywords: Diarrhea, Oral Rehydration Therapy, management, Knowledge, Structured Teaching Programme, Effectiveness, mothers of under five children.

\section{Introduction}

Diarrhea means passage of 3 or more loose or watery motions per 24 hours, resulting in excessive loss of fluid and electrolytes in stools. The signs of dehydration due to diarrhea remain unnoticed by the majority of mothers. Studies conducted all over the world, particularly in Bangladesh, India and Indonesia, have establish the value to this "Revolutionary concept" in counteracting dehydration which is known to be the main cause of deaths in acute diarrheal disease. Mothers basic knowledge about diarrhea depends on various factors such as educational status prior experience of managing the disease and even ethnicity. ${ }^{[3]}$

Mother in the family occupies pivotal role. If mother is educated and having significant health awareness she will take the responsibility of increasing total family awareness which facilitates high standard of living. If mother having the knowledge about healthy practices such as hygienic weaning practices, safe drinking water improved nutrition and adopt the healthy practices by the mothers can raise the healthful living condition and decreases the morbidity and mortality rate of children. ${ }^{[4]}$

\section{Objectives:}

1. To assess the pre-test knowledge regarding the oral rehydration therapy in management of diarrhea among mothers of under five children in control and experimentalgroup.

2. To assess the post-test knowledge regarding the oral rehydration therapy in management of diarrhea among mothers of under five children in control and experimentalgroup. 
3. To compare the pre-test and post-test knowledgeregarding the oral rehydration therapy in management of diarrhea among mothers of under five children in controland experimental group.

4. To find out the relationship of pre-test and post-test knowledge regarding the oral rehydration therapy in management of diarrhea among mothers of under five children in control and experimental group with selected demographic variables.

\section{Methodology}

Approach: Quasi experimental research approach

Design: Nonequivalent pre-test, post-test research design

Population: Mothers of under five children.

Sample Size: 40

Sampling Technique: Purposive Sampling Technique (NonRandom Sampling)

\section{MATERIAL \& METHOD}

The present study was conducted at selected a community under PHC of Jerthi (Subash Nagar) Sikar, Rajasthan. The total sample consisted of forty mothers of under five children, twenty in control group and twenty in experimental group. Pre-test of control group was taken with the help of structured questionnaire to assess their knowledge regarding the oral rehydration therapy in management of diarrhea followed by a post-test after seven days. To avoid contamination pre-test and structured teaching toexperimental group was given after post-test of controlgroup. Post-test of experimental group was also taken after seven days.

The demographic variables included in the study were education status of mother, occupation, income, No. of children, education of husband, occupation of husband, type of family, health status of mother and size of family.

\section{Plan for data analysis}

Descriptive statistics: Mean, Mean percentage \&Standard deviation.

Inferential Statistics: Chi square, Paired 't' test, unpaired ' $t$ ' test and ANOVA (F).

\section{MAJOR FINDINGS}

- In experimental group majority of mothers (36.67\%) are 20-25 age group whereas In control group majority of mothers (33.3\%) are 25-30 year of age. In experimentalgroup majorityof mothers (36.67\%) are higher secondary and incontrol group majority of mothers (26.6\%) are higher secondary. In experimental group majority of mothers $(36.67 \%)$ are belong 2 children whereas in control group majority of mothers $(33.3 \%)$ are belong 3 children.

- Regarding the comparison of pre-test and post-testmean knowledge score of mothers in control and experimental group, the pre-test and post-testmean knowledge score of control group $(26.52,25.04)$ was not statistically significant, whereas the pre-test and post-test mean knowledge score ofexperimental group $(24.15,35.50)$ was highlysignificant at $\mathrm{p}<0.001$.

- Thus it was concluded that structured teachingprogram had definite impact to increase theknowledge level of mothers in experimentalgroup.

- According to percentage distribution, in controlgroup majority of mothers had below average pretest (74\%) and post-test (84\%) knowledge scorewhereas in experimental group (74\%) had belowaverage pre-test knowledge score followed by $(20 \%)$ excellent, $(75 \%)$ good and $(5 \%)$ average posttestknowledge score.

- According to areas of knowledge, in control group both pre-test and post-test mean knowledge scoreof mothers was lowest in the area of prevention $(41.17 \%),(40.50 \%)$ followed by risk factors $(51.58 \%)$, $(53.66 \%)$ and general information of ORS therapy $(56.66 \%),(58.89 \%)$ respectively.Similarly in experimental group pre -test mean knowledge scoreof mothers was lowest in area of prevention (44.83\%), followed by risk factors (51.56\%) andgeneral information of ORS therapy (59.33\%). Whereas the post-testmean knowledge score was highest in the area ofgeneral information of ORS therapy $(77.33 \%)$ followed byprevention $(74.00 \%)$ and risk factors $(71.56 \%)$ respectively.

- There was statistically significant effect of education status of mother, occupation, income, No. of children, education of husband, occupation of husband, type of family, health status of mother and size of family regarding the oral rehydration therapy in management of diarrhea in control andexperimental group.

\section{Conclusion}

The study concluded that the difference between pre-test mean knowledge score of control and experimental group was statistically non-significant at $\mathrm{p}<0.05$ whereas the difference between post-test mean knowledge score of both groups was statistically highly significant at $p<0.001$. It was thus concluded that 
structured teaching was effective in raising the posttest knowledge level of mothers of under five children in experimental group.

\section{Acknowledgements}

My heartfelt thanks to Almighty and all the individuals who had been a source of inspiration, guidance and support from the conception of this research to study completion.

\section{Conflict of Interest: None}

Ethical Consideration: An informed verbal consent was obtained from each study subject. It was ensuredthat treatment of child was not interfered and confidentiality and anonymity of each subject was ensured.

Source of Funding: None

\section{References}

[1]. Sample Registration System: Special Survey of Deaths. Report on Causes of Death: 2001-03, Office of Registrar General of India, Ministry of Home Affairs, New Delhi. 2009

[2]. BT Basavanthappa, "Nursing Research" 2nd Edition, Jaypee brother's medical publishers Ltd New Delhi, 2010.

[3]. Dorthy R. Marlow, Barbara A. Redding "Textbook of pediatric nursing" 6th edition, , Elsevier ,a division of reed Elsevier India private limited ,New Delhi, 2010.

[4]. Rimple Sharma "Essential of pediatric nursing" 1st edition, , Jaypee brothers medical publishers Ltd Newdelhi,2013 